February 2000 - NREL/CP-500-26338

\title{
Understanding the Unbalanced-Voltage Problem in Wind Turbine Generation
}

E. Muljadi, C.P. Butterfield, T. Batan, and D. Yildirim

Presented at the 1999 IEEE Industry Applications Society Annual Meeting

Phoenix, Arizona October 3-7, 1999
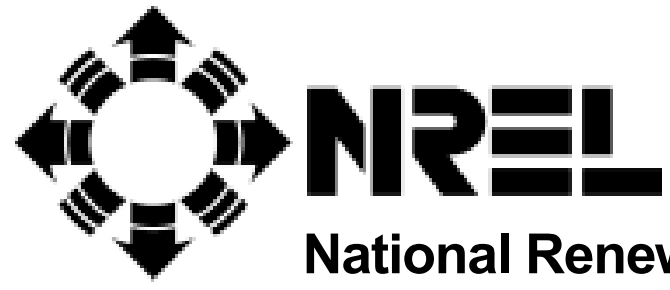

National Renewable Energy Laboratory

1617 Cole Boulevard

Golden, Colorado 80401-3393

NREL is a U.S. Department of Energy Laboratory

Operated by Midwest Research Institute $\bullet$ Battelle $\bullet$ Bechtel

Contract No. DE-AC36-99-G010337 


\section{NOTICE}

The submitted manuscript has been offered by an employee of the Midwest Research Institute (MRI), a contractor of the US Government under Contract No. DE-AC36-99G010337. Accordingly, the US Government and MRI retain a nonexclusive royalty-free license to publish or reproduce the published form of this contribution, or allow others to do so, for US Government purposes.

This report was prepared as an account of work sponsored by an agency of the United States government. Neither the United States government nor any agency thereof, nor any of their employees, makes any warranty, express or implied, or assumes any legal liability or responsibility for the accuracy, completeness, or usefulness of any information, apparatus, product, or process disclosed, or represents that its use would not infringe privately owned rights. Reference herein to any specific commercial product, process, or service by trade name, trademark, manufacturer, or otherwise does not necessarily constitute or imply its endorsement, recommendation, or favoring by the United States government or any agency thereof. The views and opinions of authors expressed herein do not necessarily state or reflect those of the United States government or any agency thereof.

Available electronically at http://www.doe.gov/bridge

Available for a processing fee to U.S. Department of Energy and its contractors, in paper, from:

U.S. Department of Energy

Office of Scientific and Technical Information

P.O. Box 62

Oak Ridge, TN 37831-0062

phone: 865.576 .8401

fax: 865.576.5728

email: reports@adonis.osti.gov

Available for sale to the public, in paper, from:

U.S. Department of Commerce

National Technical Information Service

5285 Port Royal Road

Springfield, VA 22161

phone: 800.553 .6847

fax: 703.605.6900

email: orders@ntis.fedworld.gov

online ordering: http://www.ntis.gov/ordering.htm

Printed on paper containing at least $50 \%$ wastepaper, including $20 \%$ postconsumer waste 


\title{
Understanding the Unbalanced-Voltage Problem in Wind Turbine Generation
}

\author{
E. Muljadi, Senior Member, IEEE, \\ D. Yildirim, Student Member, IEEE
}

\author{
T. Batan, Student Member, IEEE \\ C. P. Butterfield, Member, IEEE
}

\author{
National Renewable Energy Laboratory \\ 1617 Cole Boulevard \\ Golden, CO 80401 \\ Tel. (303)384-6900, Fax (303)384-6999 \\ Eduard_muljadi@nrel.gov,http://www.nrel.gov/wind
}

\begin{abstract}
Most wind turbines are equipped with line-connected induction generators. Induction generators are very attractive as wind turbine generators due to their low cost, ruggedness, and the need for little or no maintenance. At constant frequency, the induction generator operates in a small range of speeds and, therefore, it operates with a small range of slips with respect to synchronous speed. Compared to a synchronous generator, an induction generator provides lower stiffness, thus alleviating the mechanical stress.

In a weak power system network, an unbalanced load at the distribution lines can cause unbalanced voltage conditions. If an induction generator is connected to an unbalanced voltage, the resulting stator current will be unbalanced. The unbalanced current creates unequal heating (hot spots) on the stator winding. The heat may increase the winding temperature, which degrades the insulation of the winding, i.e., the life expectancy of the winding. Unbalanced currents also create torque pulsation on the shaft resulting in audible noise and extra mechanical stress.

This paper explores the unbalanced voltage problem in induction generator. The levels of unbalance and the loads are varied. Experimental and predicted results are presented in this paper.
\end{abstract}

INDEX TERMS

Unbalanced-voltages, induction generators, wind energy.

\section{INTRODUCTION}

Wind power generation has become increasingly popular in the past few years. Wind turbines have been used for many centuries. In the United States, the use of wind power for electrical generation was not started in a major way until the beginning of the 1970s during the energy crisis. Many applications are related to large-scale, utility-size wind parks where thousands of wind turbines are interconnected to generate large-scale electricity. In some other parts of the world, wind turbines are installed on a smaller scale.

Using wind turbines at the end of long transmission lines in rural areas is not uncommon. Many wind turbines are connected to weak power systems where unbalanced-load distributions are not corrected for many months. This persistence or lingering of an unbalanced condition poses serious problems to the induction generator. In this paper, the problem has been studied and the impact on reducing an unbalanced condition is investigated. The unequal heat loss, output power reduction, and torque pulsation will be presented and compared.

\section{UNBALANCED OPERATION}

Unbalanced operation of induction and synchronous machines has been the source of heating problems and reduced efficiency. A major cause of an unbalanced voltage at the point of utilization is typically single-phase loads in a system which are not uniformly applied to all three phases. This is particularly true for rural electric power systems having long distribution lines and fed by induction generators driven by wind turbines. Unbalanced voltage problems also occur in large urban power systems where heavy single-phase demands, particularly lighting loads, are imposed in large commercial facilities. A large manufacturing plant may have a well-balanced incoming supply of voltage, but unbalanced conditions can develop within the plant from its own singlephase power requirements if the loads are not uniformly spread among the three phases. An unbalanced-voltage condition can also be caused by unsymmetrical transformer windings or transmission impedance, open wye, open delta, unbalanced loads in the transmission lines, and many other causes [1], [2].

Figure 1 illustrates the connection diagram of an induction generator driven by a wind turbine at the end of a weak power system or a long transmission line. Unbalanced loads represent many single-phase loads, which are common in rural and residential applications. Unbalanced loading at the point of common coupling (PCC) can cause unbalancedvoltage drop across the transmission line, which will result in unbalanced voltages at PCC.

While the unbalanced-phase voltage is small, large negative-sequence currents can result due to low negativesequence impedance of an induction generator. These large currents eventually can cause unbalanced heating (hot spots) in the machine windings, which can potentially lead to 


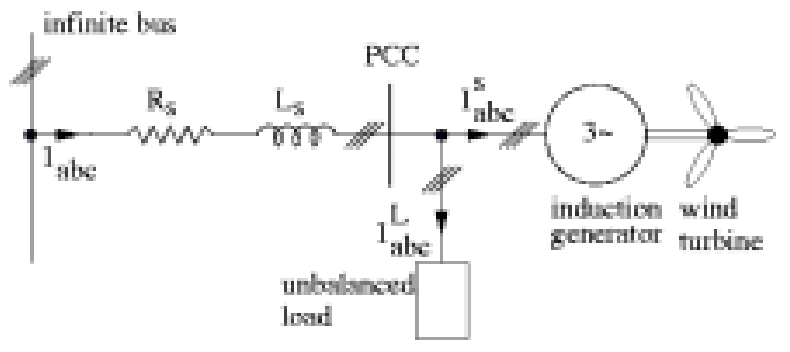

Figure 1. Physical connection in the power system

failure. Unbalanced-voltage operation will also create a pulsating torque which produces speed pulsation, mechanical vibration, and consequently, acoustic noise.

\section{METHOD OF ANALYSIS}

\section{A. Steady-State Analysis}

One of the methods for the steady-state analysis of an unbalanced operation of an induction machine is to employ the symmetrical component theory [3] leading to positive-, negative- and zero-sequence equivalent circuits for the induction generator. Since the neutral point of the stator winding is not grounded, the zero-sequence quantities do not exist. The steady-state positive- and negative-sequence rotor currents, calculated from the equivalent circuits shown in Figure 2, are used to compute the developed per unit torque of the machine.

$$
\begin{aligned}
& T_{p}=\frac{1}{\omega_{s}}\left|I_{r p}\right|^{2} \frac{r_{r}}{s} \\
& T_{n}=\frac{1}{-\omega_{s}}\left|I_{r n}\right|^{2} \frac{r_{r}}{2-s}
\end{aligned}
$$

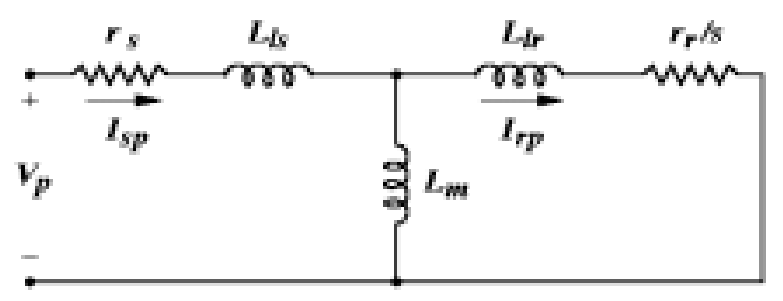

(a)

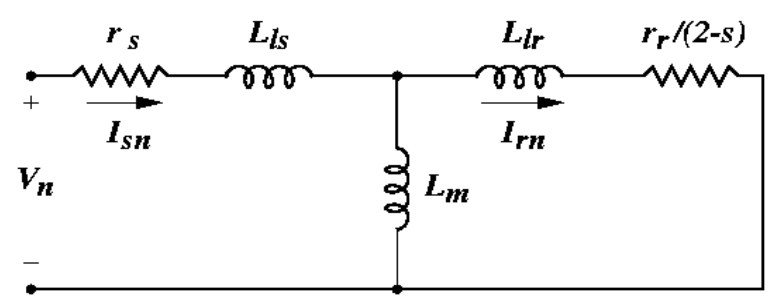

(b)

Figure 2. (a) Positive and (b) negative sequence equivalent circuits of an induction machine
One can calculate the copper losses in stator and rotor windings for each phase by applying inverse transformation to the positive- and negative-sequence currents. Equations 1 and 2 are used to obtain the total resultant torque $\left(T=T_{p}+T_{n}\right.$ ) of the machine. Note that the negative torque opposes the positive torque.

\section{B. Dynamic Analysis}

A dynamic analysis is necessary in order to see the effects of unbalanced voltages on the performance of the generator, e.g., torque pulsation, ripples in speed, and currents. In this analysis, the voltages and currents are transformed into an arbitrary reference frame [4] by

$$
\mathbf{f}_{\mathrm{qdo}}=\mathbf{K}_{\mathrm{s}} \mathbf{f}_{\mathrm{abc}}
$$

where f's are voltages or currents and $\mathrm{K}_{\mathrm{s}}$ is defined as

$$
\mathbf{K}_{\mathrm{s}}=\frac{2}{3}\left[\begin{array}{ccc}
\cos (\theta \mathrm{o} & \cos \left(\theta-\frac{2 \pi}{3}\right) & \cos \left(\theta+\frac{2 \pi}{3}\right) \\
\sin (\theta \mathrm{i} & \sin \left(\theta-\frac{2 \pi}{3}\right) & \sin \left(\theta+\frac{2 \pi}{3}\right) \\
\frac{1}{2} & \frac{1}{2} & \frac{1}{2}
\end{array}\right]
$$

The arbitrary reference-frame equivalent circuits of an induction machine are illustrated in Figure 3, where $v_{q s}$ and $v_{d s}$ are the applied stator voltages, $\omega$ is the speed of reference frame, $\omega_{r}$ is the rotor speed, $r_{s}$ and $L_{l s}$ are the stator resistance and leakage inductance, respectively, $r_{r}$ and $L_{l r}$ are for the rotor windings, $L_{m}$ is the magnetizing inductance.

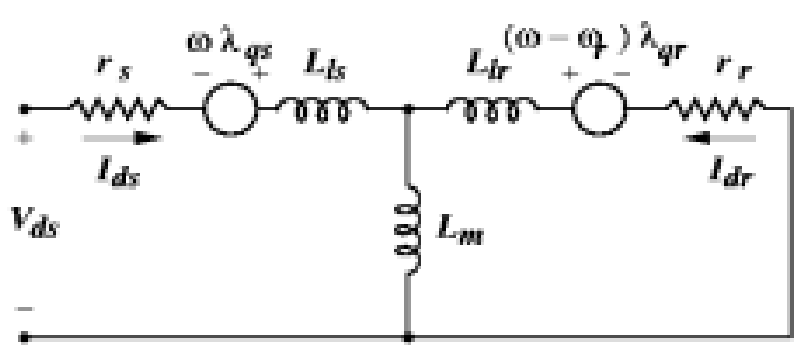

(a)

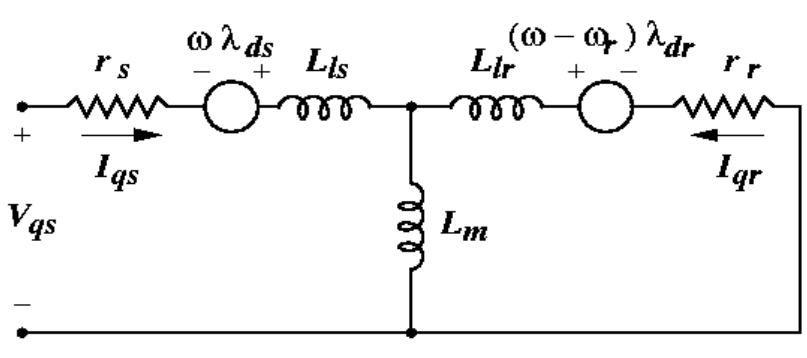

(b)

Figure 3. (a) d-and (b) q-axis equivalent circuits of a three-phase induction machine in arbitrary referenceframe with rotor voltages equal to zero 
The flux equations can be written as

$$
\begin{aligned}
& \lambda_{\mathrm{qs}}=\mathrm{L}_{\mathrm{ls}} \mathrm{i}_{\mathrm{qs}}+\mathrm{L}_{\mathrm{m}}\left(\mathrm{i}_{\mathrm{qs}}+\mathrm{i}_{\mathrm{qr}}\right) \\
& \lambda_{\mathrm{ds}}=\mathrm{L}_{\mathrm{ls}} \mathrm{i}_{\mathrm{ds}}+\mathrm{L}_{\mathrm{m}}\left(\mathrm{i}_{\mathrm{ds}}+\mathrm{i}_{\mathrm{dr}}\right) \\
& \lambda_{\mathrm{qr}}=\mathrm{L}_{\mathrm{lr}} \mathrm{i}_{\mathrm{qr}}+\mathrm{L}_{\mathrm{m}}\left(\mathrm{i}_{\mathrm{qs}}+\mathrm{i}_{\mathrm{qr}}\right) \\
& \lambda_{\mathrm{dr}}=\mathrm{L}_{\mathrm{lr}} \mathrm{i}_{\mathrm{dr}}+\mathrm{L}_{\mathrm{m}}\left(\mathrm{i}_{\mathrm{ds}}+\mathrm{i}_{\mathrm{dr}}\right)
\end{aligned}
$$

The system equations in the stationary reference frame can then be written from the equivalent circuit of Figure 3:

$$
\begin{gathered}
\mathrm{v}_{\mathrm{qs}}=\frac{\mathrm{r}_{\mathrm{s}}}{\mathrm{X}_{\mathrm{ls}}}\left(1-\frac{\mathrm{X}_{\mathrm{aq}}}{\mathrm{X}_{\mathrm{ls}}}\right) \psi_{\mathrm{qs}}+\frac{\mathrm{p}}{\omega_{\mathrm{b}}} \psi_{\mathrm{qs}}-\frac{\mathrm{r}_{\mathrm{s}}}{\mathrm{X}_{\mathrm{ls}}} \frac{\mathrm{X}_{\mathrm{aq}}}{\mathrm{X}_{\mathrm{lr}}} \psi_{\mathrm{qr}} \\
\mathrm{v}_{\mathrm{ds}}=\frac{\mathrm{r}_{\mathrm{s}}}{\mathrm{X}_{\mathrm{ls}}}\left(1-\frac{\mathrm{X}_{\mathrm{ad}}}{\mathrm{X}_{\mathrm{ls}}}\right) \psi_{\mathrm{ds}}+\frac{\mathrm{p}}{\omega_{\mathrm{b}}} \psi_{\mathrm{ds}}-\frac{\mathrm{r}_{\mathrm{s}}}{\mathrm{X}_{\mathrm{ls}}} \frac{\mathrm{X}_{\mathrm{ad}}}{\mathrm{X}_{\mathrm{lr}}} \psi_{\mathrm{dr}} \\
\mathrm{v}_{\mathrm{qr}}=\frac{\mathrm{r}_{\mathrm{s}}}{\mathrm{X}_{\mathrm{lr}}}\left(1-\frac{\mathrm{X}_{\mathrm{aq}}}{\mathrm{X}_{\mathrm{lr}}}\right) \psi_{\mathrm{gr}}+\frac{\mathrm{p}}{\omega_{\mathrm{b}}} \psi_{\mathrm{gr}}-\frac{\mathrm{r}_{\mathrm{r}}}{\mathrm{X}_{\mathrm{lr}}} \frac{\mathrm{X}_{\mathrm{aq}}}{\mathrm{X}_{\mathrm{ls}}} \psi_{\mathrm{qs}}-\frac{\omega_{\mathrm{r}}}{\omega_{\mathrm{b}}} \psi_{\mathrm{dr}} \\
\mathrm{v}_{\mathrm{dr}}=\frac{\mathrm{r}_{\mathrm{s}}}{\mathrm{X}_{\mathrm{lr}}}\left(1-\frac{\mathrm{X}_{\mathrm{ad}}}{\mathrm{X}_{\mathrm{lr}}}\right) \psi_{\mathrm{dr}}+\frac{\mathrm{p}}{\omega_{\mathrm{b}}} \psi_{\mathrm{dr}}-\frac{\mathrm{r}_{\mathrm{r}}}{\mathrm{X}_{\mathrm{lr}}} \frac{\mathrm{X}_{\mathrm{ad}}}{\mathrm{X}_{\mathrm{ls}}} \psi_{\mathrm{ds}}+\frac{\omega_{\mathrm{r}}}{\omega_{\mathrm{b}}} \psi_{\mathrm{qr}}
\end{gathered}
$$

where $p$ is the operator $d / d t, v_{q r}=v_{d r}=0, \omega_{b}$ is the electrical angular velocity, and

$$
X_{a q}=X_{a d}=\left(\frac{1}{X_{m}}+\frac{1}{X_{l s}}+\frac{1}{X_{l r}}\right)^{-1}
$$

In the above equations, $\psi$ 's are flux linkages per second $(\psi=(X / L) \lambda)$. The per unit rotor speed and electromagnetic torque are obtained from the following equations,

$$
\begin{aligned}
& p \frac{\omega_{r}}{\omega_{b}}=\frac{1}{2 H}\left(T_{e}-T_{L}\right) \\
& T_{e}=\left(\psi_{d s} i_{q s}-\psi_{q s} i_{d s}\right)
\end{aligned}
$$

where $i_{q s}$ and $i_{d s}$ are the stator currents in $\mathrm{q}$ and $\mathrm{d}$ axes, respectively, $H=(1 / 2)(2 / P)^{2}\left(J \omega_{b}^{2}\right) / P_{B}$ is a coefficient related to the inertia of the machine, $T_{L}$ is the load torque, $P$ is the pole number, $J$ is the inertia of the machine, and $P_{B}$ is the base power.

The stator voltages are computed from

$$
\mathbf{V}_{\mathrm{abc}}^{\mathrm{s}}=\mathbf{V}_{\mathrm{abc}}-\mathbf{R}_{\mathrm{abc}}^{\mathrm{s}} \mathbf{I}_{\mathrm{abc}}-\mathbf{X}_{\mathrm{abc}}^{\mathrm{s}} \frac{\mathrm{p}}{\omega_{\mathrm{b}}} \mathbf{I}_{\mathrm{abc}}
$$

where $\mathbf{V}_{\text {abc }}$ and $\mathbf{V}_{\text {abc }}{ }^{\mathbf{s}}$ are the phase voltages at the infinite bus and at the stator terminals of the induction generator, respectively, $\mathbf{I}_{\mathbf{a b c}}$ is the line current of power system, $\mathbf{R}_{\mathbf{a b c}}{ }^{\mathbf{s}}$ and $\mathbf{X}_{\mathbf{a b c}}{ }^{\mathbf{s}}$ are the diagonal matrices consisting of transmission line resistances and reactances, respectively. Assuming a delta-connected load, the stator voltages of an induction generator can also be written in terms of the load currents,

$$
\mathbf{C}_{\mathbf{v}} \mathbf{V}_{\mathrm{abc}}^{\mathrm{s}}=\mathbf{R}_{\mathrm{abc}}^{\mathrm{L}} \mathbf{I}_{\mathrm{abc}}^{\mathbf{\Delta}}+\mathbf{X}_{\mathrm{abc}}^{\mathrm{L}} \frac{\mathrm{p}}{\omega_{\mathrm{b}}} \mathbf{I}_{\mathrm{abc}}^{\mathbf{\Delta}}
$$

where

$$
\mathbf{C}_{\mathbf{v}}=\left[\begin{array}{ccc}
1 & -1 & 0 \\
0 & 1 & -1 \\
-1 & 0 & 1
\end{array}\right]
$$

is the transformation matrix of line-to-line voltages to phase voltages at the stator of the machine, $\mathbf{R}_{\mathbf{a b c}}{ }^{\mathbf{L}}$ and $\mathbf{X}_{\mathbf{a b c}}{ }^{\mathbf{L}}$ are the diagonal matrices consisting of load resistances and reactances, respectively, and $\mathbf{I}_{\mathbf{a b c}}{ }^{\boldsymbol{\Delta}}$ is the load current inside the delta. The current of the power system is equal to

$$
\mathbf{I}_{\mathrm{abc}}=\mathbf{C}_{\mathrm{i}} \mathbf{I}_{\mathrm{abc}}^{\mathbf{u}}+\mathbf{I}_{\mathrm{abc}}^{\mathrm{s}}
$$

where $\mathbf{I}_{\mathbf{a b c}}{ }^{\mathbf{s}}$ is the stator current of the induction generator and

$$
\mathbf{C}_{\mathbf{i}}=\left[\begin{array}{ccc}
1 & 0 & -1 \\
-1 & 1 & 0 \\
0 & -1 & 1
\end{array}\right]
$$

is the transformation matrix of load currents inside delta to the line current of load $\mathbf{I}_{\mathbf{a b c}}{ }^{\mathbf{L}}$. Transforming Equations 10,11 , and 12 into the stationary reference frame using Equation 3 yields

$$
\begin{aligned}
& \mathbf{V}_{q d o}^{\mathrm{s}}=\mathbf{V}_{q d o}-\mathbf{R}_{\mathbf{q d o}}^{\mathrm{s}} \mathbf{I}_{\text {qdo }}-\mathbf{X}_{\mathbf{q d o}}^{\mathrm{s}} \frac{\mathrm{p}}{\omega_{\mathrm{b}}} \mathbf{I}_{\text {qdo }} \\
& \mathbf{I}_{\text {qdo }}^{\Delta}=\mathbf{R}_{\text {qdo }}^{\mathrm{L}} \mathbf{V}_{\text {qdo }}^{\mathrm{s}}-\mathbf{X}_{\mathrm{qdo}}^{\mathrm{L}} \frac{\mathrm{p}}{\omega_{\mathrm{b}}} \mathbf{I}_{\text {qdo }}^{\Delta} \\
& \mathbf{I}_{q d o}=K_{s} C_{i} K_{s}^{-1} I_{q d o}^{\Delta}+I_{q d o}^{s}
\end{aligned}
$$

where

$$
\begin{aligned}
& \mathbf{R}_{\mathbf{q d o}}^{\mathrm{s}}=\mathbf{K}_{\mathrm{s}} \mathbf{R}_{\mathrm{abc}}^{\mathrm{s}} \mathbf{K}_{\mathrm{s}}^{-1} \\
& \mathbf{X}_{\mathbf{q d o}}^{\mathrm{s}}=\mathbf{K}_{\mathrm{s}} \mathbf{X}_{\mathrm{abc}}^{\mathrm{s}} \mathbf{K}_{\mathrm{s}}^{-1} \\
& \mathbf{R}_{\mathrm{qdo}}^{\mathrm{L}}=\mathbf{K}_{\mathrm{s}}\left(\mathbf{R}_{\mathrm{abc}}^{\mathrm{L}}\right)^{-1} \mathbf{C}_{\mathrm{v}} \mathbf{K}_{\mathrm{s}}^{-1} \\
& \mathbf{X}_{\mathbf{q d o}}^{\mathbf{L}}=\mathbf{K}_{\mathrm{s}}\left(\mathbf{R}_{\mathrm{abc}}^{\mathrm{L}}\right)^{-1} \mathbf{X}_{\mathrm{abc}}^{\mathrm{L}} \mathbf{K}_{\mathrm{s}}^{-1}
\end{aligned}
$$

In Equations 13, 14, 15, the zero-sequence quantities are assumed to be zero because the neutral point of the induction generator is not grounded. The block diagram describing the above equations is depicted in Figure 4. System equations 4 through 8 , along with 14 , can be solved using numerical analysis methods. In order to illustrate the effect of the unbalanced loading, a variable-resistive load is applied at the PCC. The system is then analyzed and the results are tabulated in Table I. In this table, the load on phases a and b 


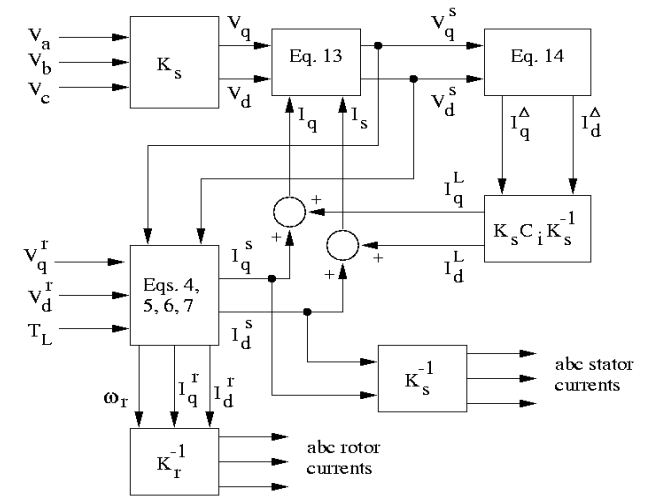

Figure 4. Block diagram of the system under investigation

are kept at $1.0 \mathrm{pu}$ while the load connected to phase $\mathrm{c}$ is varied from $0.2 \mathrm{pu}$ to $1.8 \mathrm{pu}$. It is shown that any unbalanced-load condition generates unbalanced voltages at PCC. The level of unbalance is shown by the size of the negative voltage, $V_{n}$.

\begin{tabular}{|c|c|c|c|c|c|}
\hline & & $\begin{array}{r}\mathrm{Tab} \\
\text { TAGES FC }\end{array}$ & & & \\
\hline $\begin{array}{c}\mathrm{Z}_{\mathrm{a}}=\mathrm{Z}_{\mathrm{b}}=1 \mathrm{pu} \\
\mathrm{Z}_{\mathrm{c}}(\mathrm{pu})\end{array}$ & $\begin{array}{l}V_{\text {an }} \\
\text { (V) }\end{array}$ & $\begin{array}{l}V_{b n} \\
\text { (V) }\end{array}$ & $\begin{array}{l}V_{c n} \\
\text { (V) }\end{array}$ & $\begin{array}{l}V_{p} \\
\text { (V) }\end{array}$ & $\begin{array}{l}V_{n} \\
\text { (V) }\end{array}$ \\
\hline$\overline{0.2}$ & 218.88 & 242.77 & 231.07 & 230.7 & 13.8 \\
\hline 0.4 & 236.12 & 245.8 & 241.14 & 240.99 & 5.58 \\
\hline 0.8 & 245.76 & 247.44 & 246.64 & 246.61 & 0.97 \\
\hline 1 & 247.77 & 247.77 & 247.77 & 247.77 & 0 \\
\hline 1.2 & 249.13 & 248 & 248.54 & 248.56 & 0.65 \\
\hline 1.4 & 250.11 & 248.16 & 249.1 & 249.12 & 1.13 \\
\hline 1.8 & 251.43 & 248.33 & 249.82 & 249.86 & 1.79 \\
\hline
\end{tabular}

\section{RESULT AND DISCUSSIONS}

In real power systems, an unbalanced condition can happen even if the voltage at the point of generation is balanced. As an example, consider Figure 1 presented above where an infinite bus (balanced three phase) is connected to a long distribution line or line feeder (high transmission impedance) connected to an unbalanced village load.

Due to voltage drop along the transmission line, the voltage at the receiving end (customer) will be unbalanced. Thus, if there is an induction generator connected to this point, the induction generator will be exposed to an unbalanced condition.

A set of laboratory experiments was performed to observe the unbalanced condition affecting the induction generator. The laboratory experiments were performed using a smallscale induction generator driven by a DC motor. The induction generator is connected to unbalanced line voltages. The unbalanced source was implemented using three variacs (variable auto transformers) set at different voltages. Figure 5 shows the experimental setup of the three-phase unbalanced condition. The DC motor is connected to a variable DC

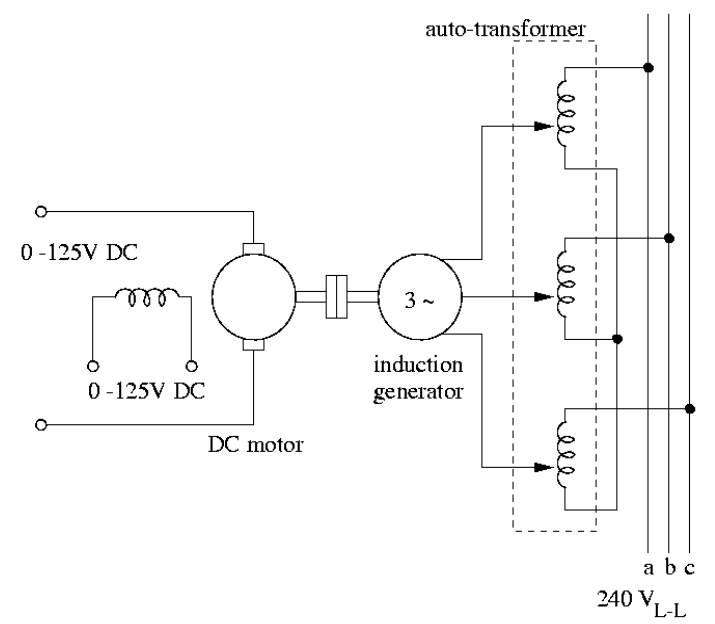

Figure 5. Experimental setup to create unbalanced voltage

supply. Thus, the speed of the DC motor can be adjusted by controlling the DC-armature voltage of the motor. In this experiment, the rotor speed is controlled at $1865 \mathrm{rpm}$.

\begin{tabular}{|c|c|c|c|c|c|c|c|c|}
\hline \multicolumn{3}{|c|}{ COMPARISON OF MEASURED AND COMPUTED VALUES OF STATOR CURRENTS } \\
\hline \multicolumn{3}{|c|}{$\begin{array}{c}\text { Stator voltages } \\
\text { (V) }\end{array}$} & \multicolumn{3}{c|}{$\begin{array}{c}\text { Stator currents } \\
\text { measured (A) }\end{array}$} & \multicolumn{3}{c|}{$\begin{array}{c}\text { Stator currents } \\
\text { computed (A) }\end{array}$} \\
\hline $\mathrm{V}_{\mathrm{an}}$ & $\mathrm{V}_{\mathrm{bn}}$ & $\mathrm{V}_{\mathrm{cn}}$ & $\mathrm{I}_{\mathrm{as}}$ & $\mathrm{I}_{\mathrm{bs}}$ & $\mathrm{I}_{\mathrm{cs}}$ & $\mathrm{I}_{\text {as }}$ & $\mathrm{I}_{\mathrm{bs}}$ & $\mathrm{I}_{\mathrm{cs}}$ \\
\hline 101.2 & 100 & 106 & 1.86 & 1.39 & 1.65 & 1.88 & 1.4 & 1.72 \\
104.9 & 104.1 & 107.6 & 1.81 & 1.57 & 1.68 & 1.84 & 1.56 & 1.73 \\
107.3 & 106.5 & 107.4 & 1.75 & 1.72 & 1.68 & 1.77 & 1.71 & 1.71 \\
113.3 & 112 & 107 & 1.63 & 2.11 & 1.7 & 1.68 & 2.08 & 1.66 \\
117 & 116.8 & 107.4 & 1.59 & 2.4 & 1.75 & 1.57 & 2.31 & 1.74 \\
\hline
\end{tabular}

The data points were taken by keeping one phase voltage, $V_{c n}$, constant at 107 volts and varying the other two phases, $V_{a n}$ and $V_{b n}$, from 101 volts to 117 volts. While an effort to equalize $V_{a n}$ and $V_{b n}$ was not completely achieved, nevertheless the voltage in phase a and phase $b$ is very close in amplitude. The test results are given in Table II. Using the same input voltages, the positive-sequence voltage and the negative-sequence voltages were computed. The positive- and negative-sequence currents were also computed by using positive- and negative-sequence equivalent circuits. The phase currents were reconstructed and tabulated in Table II. It is shown that the experimental results and the computed results agree very closely.

Figure 6 shows the variation of the rms (root mean square) values of line currents with respect to the degree of unbalance

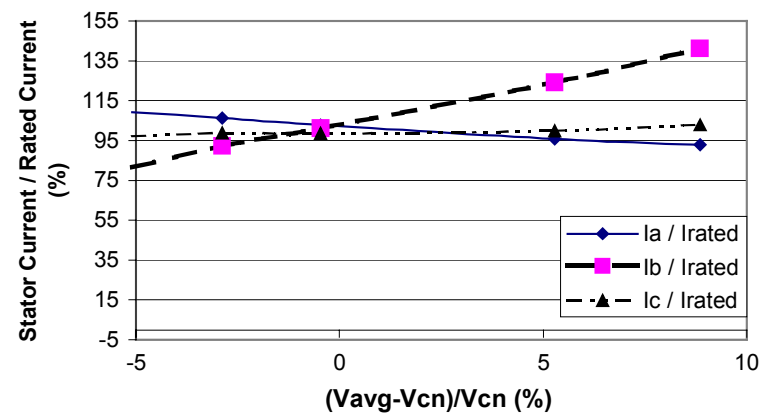

Figure 6. Stator currents versus percent voltage unbalance 


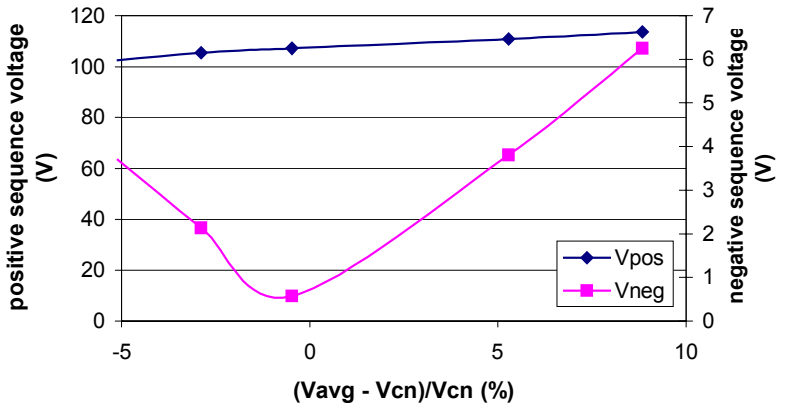

Figure 7. Positive- and negative-sequence voltages versus percent voltage unbalance

( $V_{a v g}$ is the average value of $V_{a n}$ and $V_{b n}$ ). It is shown that the three phase currents are deviating from rated current as the level of unbalance is changed. The crossing points occur only in the balanced region when the three phase voltages are equal.

The positive-sequence voltage and the negative-sequence voltage are illustrated in Figure 7 . It is shown how the negative-sequence voltage varies when the voltage in two phases is varied from $-5 \%$ below to $+9 \%$ above constant voltage (107 volts). The negative-sequence voltage varies from $0 \%$ to $5.6 \%$ of the rated voltage while the positive sequence varies from $93 \%$ to $107 \%$. It is shown in Figure 6 how the variation of negative-sequence voltage affects the balance of the three phase currents. For example, one of the phase currents reaches about $40 \%$ above rated current with only $6 \%$ negative voltage.

The effect of negative-sequence voltage on the negativesequence current produced by a generator is illustrated in Figure 8. The measured and the computed values are matched closely. It is shown that the negative-sequence currents vary with the size of negative-sequence voltage almost linearly. At $6 \%$ negative-sequence voltage, the resulting negative-sequence current is about 30\%. This relationship can be explained by using the negative-sequence equivalent circuit in Figure 2. It is easy to see that the rotor

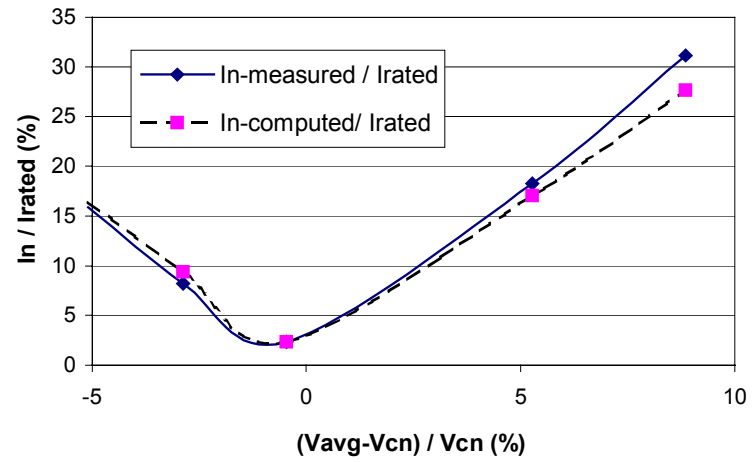

Figure 8. Negative sequence current versus percent unbalanced voltage

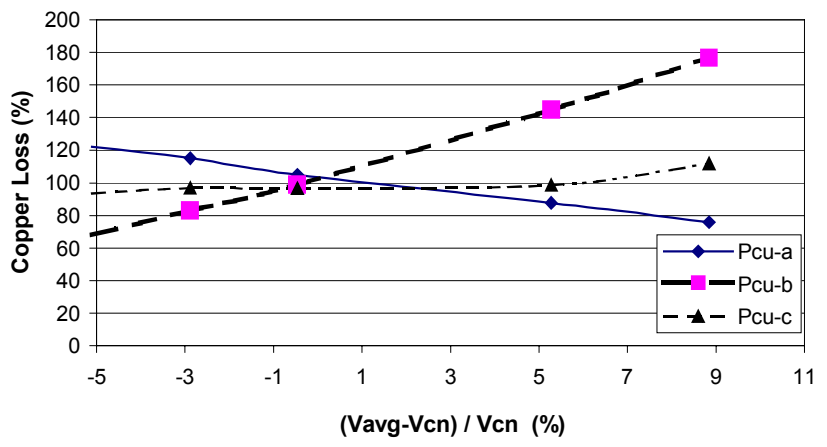

Figure 9. Copper loss in each phase versus voltage unbalance

branch has a very low impedance compared to the magnetizing branch.

The term $R_{r} /(2-s)$ will always be a small number considering the normal operating slip of an induction machine is below $10 \%$. Thus, in the normal operating slips, the negative-sequence equivalent circuit has practically constant impedance. In a simplified model, the negativesequence equivalent circuit can be approximately described by opening the magnetizing branch and replacing the term $R_{r} /(2-s)$ with $R_{r} / 2$.

With this simplified model, it is easy to see that the negative-sequence voltage varies linearly with the resulting negative-sequence current. The negative-sequence equivalent circuit impedance consists of only stator and rotor resistance and leakage inductance, which all have very small values. Therefore, a small negative-sequence voltage can produce a very large negative-sequence current. From an electricalcomponent point of view, the worst implication or side effect of an unbalanced condition is the unequal heating in the three phases of the stator windings. Figure 9 shows the copper losses in each phase of the induction generator fed by unbalanced sources. It is shown that the copper loss in phase $\mathrm{b}$ is almost constant in the range of unbalanced voltage under observation. If one or more phases conduct more currents than the rest of the phases, the copper loss will increase dramatically in the affected phases. For example, $50 \%$ current above rated will generate $125 \%$ power loss above rated. These losses create hot spots, which will make the winding temperature of the affected phase much higher than the rated temperature. As a result, the life of the insulation material will be much shorter than is the case with normal operation.

Unlike a short circuit condition or a balanced-overload condition, these unbalanced operations often exist for a long period of time before they are detected. The customer with single-phase applications will not be affected by the unbalanced condition. However, the customer having threephase induction motors as the load can be affected. The unbalanced voltages on the generator side may be difficult to detect in an unbalanced condition because the variations are not very significant. The detection is easier from the threephase output currents. 


\begin{tabular}{|l|c|c|}
\hline \multicolumn{3}{|c|}{ TABLE III } \\
& $\begin{array}{c}\text { MEASURED AND COMPUTED VALUES OF POSITIVE AND } \\
\text { NEGATIVE SEQUENCE CURRENTS }\end{array}$ \\
\hline & $\begin{array}{c}\text { Positive sequence } \\
\text { current, Ip (A) }\end{array}$ & $\begin{array}{c}\text { Negative sequence } \\
\text { current, In (A) }\end{array}$ \\
\hline Experimental & 1.87 & 0.53 \\
Steady-state analysis & 1.84 & 0.47 \\
Dynamic analysis & 1.84 & 0.48 \\
\hline
\end{tabular}

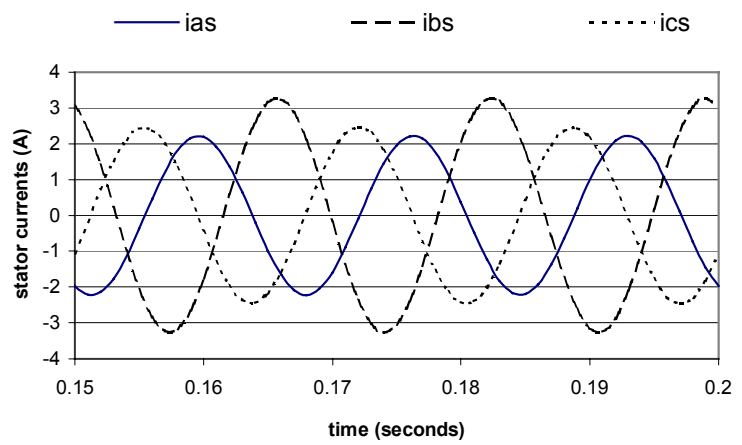

Figure 10. Computed stator phase currents under unbalanced voltages

Dynamic analysis is also performed to investigate the transient and dynamic behavior of an unbalanced-voltage operation. The case in Table II is an example illustrating the unbalanced operation of the induction generator. This particular case has a positive-sequence voltage of $1.07 \mathrm{pu}$ and a negative-sequence voltage of $5.6 \%$ and is operated at 1865 rpm.

The calculated three-phase unbalanced currents are depicted in Figure 10. Phase b current is shown to be the largest among all phase currents. As indicated from the table and the previous graphs, phase $\mathrm{b}$ will generate most of the copper losses. A comparison between measured and computed data is shown in Table III. The results of the experimental data, the steady-state analysis, and the dynamic analysis are very close.

Figure 11 illustrates the effects of the unbalanced voltages on the output torque of the machine. The size of the torque pulsation is affected by the size of the negative-sequence current. The negative sign indicates the torque is in generating mode.

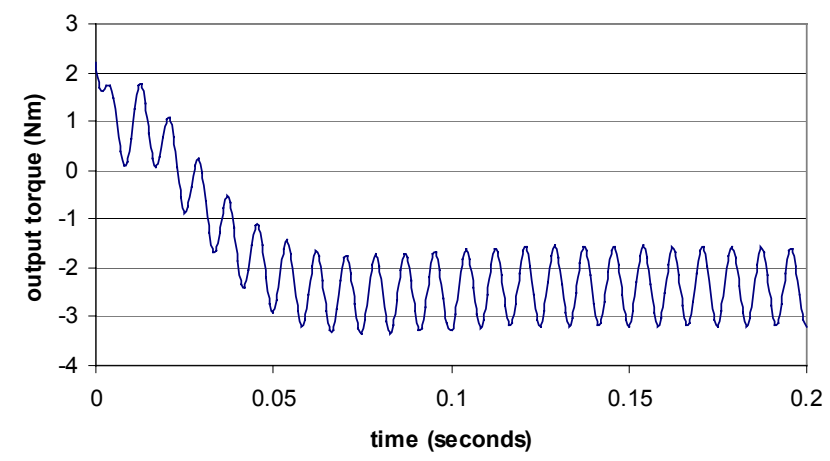

Figure 11. Computed output torque of induction generator

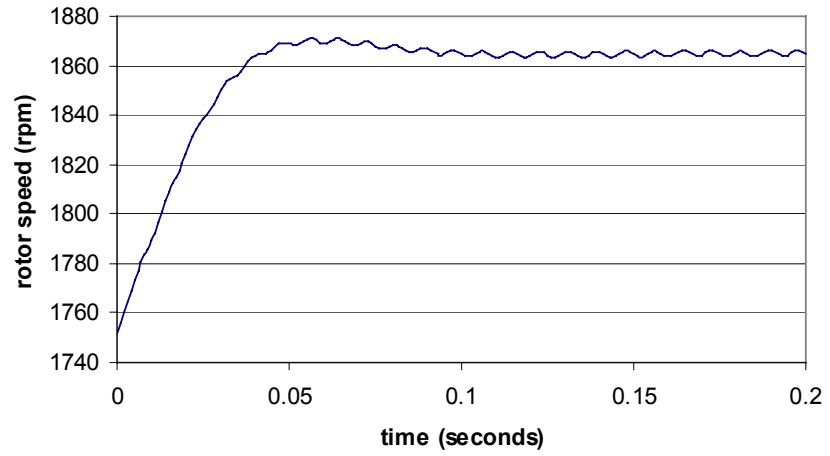

Figure 12. Calculated rotor speed of induction generator (experimental speed was $1865 \mathrm{rpm}$ )

The torque pulsation affects the mechanical strain and stress on the shaft. In wind turbine applications where the inertia of the blades is very large, the torque pulsation may not be reflected in the rotor speed. However, this torque pulsation may eventually create mechanical fatigue in mechanical components such as the gearbox and mechanical coupling or junction. In Figure 12, the inertia used in the calculation of rotor speed is reduced to show the impact of torque pulsation.

\section{CONCLUSION}

The unbalanced-voltage operation for an induction generator has been investigated. Although this mode of operation can exist for any type of prime mover, a specific case application, the wind turbine, was chosen. The steadystate as well as the dynamic calculations were investigated. Laboratory experiments were performed to verify the calculations.

The sources of unbalanced operation include

- unbalanced transmission line impedance feeding a balanced load

- unbalanced load connected to a balanced source of a weak system (high impedance).

The impacts of unbalanced voltages on the three-phase induction generators are

- unequal output currents, which generate unequal heating or hot spots on the windings due to unequal power loss

- torque pulsation, which increases fatigue load on mechanical components (gearbox), noise, and vibration.

The remedies to improve the unbalanced conditions are

- increase the power capability of transmission lines (lower transmission impedance)

- redistribute the village load periodically to equalize any unbalanced load

- use the wind turbine with a power converter on the utility side. 
The authors wish to thank Jerry Bianchi for his assistance during the test set up. We wish to acknowledge our management at NREL and the U.S. Department of Energy (DOE) for encouraging us and approving the time and tools we needed for this project. DOE supported this work under contract number DE-AC36-98-GO10337.

\section{REFERENCES}

[1] E. Muljadi, R. Schiferl, and T. Lipo, "Induction Machine Phase Balancing by Unsymmetrical Thyristor Voltage Control," IEEE Trans. on Industry Applications, Volume IA21, No.4, pp. 669-678, May/June 1985.

[2] E. Muljadi, "Induction Machine Phase Balancing by Unsymmetrical Voltage Control," Master's Thesis, University of Wisconsin at Madison, 1984.

[3] C. F. Wagner, Symmetrical Components as Applied to the Analysis of Unbalanced Electrical Circuits, McGraw-Hill, 1933, New York.

[4] P. C. Krause, Analysis of Electric Machinery, McGrawHill, 1986, New York. 